\title{
16S rDNA-PCR and Sequencing Improves Diagnosis of Bacterial Infection of the Central Nervous System
}

\author{
Katharina Boden ${ }^{*}, 1$, Svea Sachse ${ }^{1}$, Michael Baier ${ }^{1}$, Karl-Hermann Schmidt ${ }^{1}$, Michael Brodhun ${ }^{2}$, \\ Ralf Husain $^{3}$, Eberhard Straube ${ }^{1}$ and Stefan Isenmann ${ }^{4,5}$ \\ ${ }^{1}$ Institute of Medical Microbiology, ${ }^{3}$ Children's Hospital, ${ }^{4}$ Department of Neurology, Jena University Hospital, Germany \\ ${ }^{2}$ Institute of Pathology, Helios Klinikum Erfurt, Gemany \\ ${ }^{5}$ Department of Neurology, HELIOS Hospital, Wuppertal and University of Witten/Herdecke, Germany
}

\begin{abstract}
Rapid initiation of antibiotic treatment and fast diagnosis are essential in bacterial infection of the central nervous system (CNS). Culture as common method for detecting bacteria is time consuming and unreliable once antibiotic treatment has been initiated. Eubacterial 16S rDNA-PCR with species differentiation by sequencing appears to be a promising tool. Our experiences with this method performed on specimens from patients with neurological disorders between 2004 and 2006 are presented. The follow-up of 26 patients revealed bacterial infection in 12 cases (ten on effective antibiotics). The pathogen was identified in seven cases (one by culture and PCR, six by PCR alone). Additionally, two positive PCR-results failed to be sequenced, yet suggest bacterial infection. Contamination was revealed in two cases without infection, one by PCR and one by PCR and culture.

In conclusion, $16 \mathrm{~S}$ rDNA-PCR may be useful for diagnosis bacterial infection of CNS, especially after onset of antibiotic therapy.
\end{abstract}

Keywords: Broad range PCR; eubacterial PCR; 16S rDNA-PCR; meningitis; cerebral abscess; spinal infection; CNS infection, sequencing.

\section{INTRODUCTION}

In bacterial infection of the central nervous system (CNS), rapid initiation of antibiotic treatment and fast, accurate diagnosis are essential. In microbiological laboratories, the most sensitive method of detecting bacteria is culture, a time consuming procedure that is unreliable once antibiotic treatment has been initiated. To address this problem, PCR seems to be a promising tool, since it does not rely on intact, cultivable organisms. The advantage of $16 \mathrm{~S}$ rDNA-PCR followed by sequencing is the possibility to detect DNA derived from all bacteria, enabling the diagnosis of bacterial infection even where rare or unexpected organisms are the cause.

\section{PATIENTS AND METHODS}

Over a three years period, from January 2004 to December 2006, 16S rDNA-PCR was performed alongside the standard microbiological procedures on analytical samples collected in a single university centre. It was applied on all specimens form patients with suspected bacterial CNS infection where the classical microbiological tools were expected to fail, usually due to antibiotic treatment prior to sample collection. Further reasons for inclusion were unusual clinical signs with suspicion of bacterial disease but

*Address correspondence to this author at the Institute of Medical Microbiology, Jena University Hospital, Erlanger Allee 101, D-07747 Jena, Germany; Tel: 0049-3641-9393616; Fax: 0049-3641-9393502; E-mail: katharina.boden@med.uni-jena.de negative microscopy, where uncommon fastidious bacteria were expected.

Cultures were done according to conventional methods for aerobic and anaerobic bacteria, mycobacteria and fungi. In neonates, samples were additionally cultured on mycoplasma specific media (Oxoid CM 401) for one week.

At the same time PCR was performed. DNA extracted by HPPTP Kit (Roche, Mannheim) was used. To exclude contaminations during amplification, each PCR master mix was digested by restriction endonucleases $A l u I$ and Rsa I. To confirm the basic PCR conditions, negative, positive and inhibition controls were done for each sample. The primers $\mathrm{F}$ (5'ccagcagccgeggtaatacg 3') and R (5'gacgtcrtccncdccttcctc 3') amplify a 680bp-conserved region of 16S-rDNA [1]. DNA amplification was afforded by initial denaturation of $95^{\circ} \mathrm{C}$ for $5 \mathrm{~min}, 35 \mathrm{cycles}$ of $95^{\circ} \mathrm{C}$ for $30 \mathrm{sec}, 53^{\circ} \mathrm{C}$ for 30 sec and $72^{\circ} \mathrm{C}$ for $90 \mathrm{sec}$ and terminal elongation at $72^{\circ} \mathrm{C}$ for $7 \mathrm{~min}$. The product was sequenced with ABI PRISM 310 DNA-sequencer (Applied Biosystems). Sequence associations were determined by using BLAST search algorithm of GenBank database (National Centre for Biotechnology Information). Clinical data collected included clinical signs, imaging, blood/serum and cerebrospinal fluid cytology and protein, lactate analysis, response to antibiotic treatment and additional procedures.

\section{RESULTS}

27 specimens were examined from 26 patients. Patient follow-up revealed twelve patients with bacterial infection of the CNS - eight patients (9 samples) with meningitis, one 
Table 1. Clinical Data, Laboratory Findings and Microbiological Results (Cases with Confirmed CNS Infection are in Printed in Bold) of the Investigated Patients

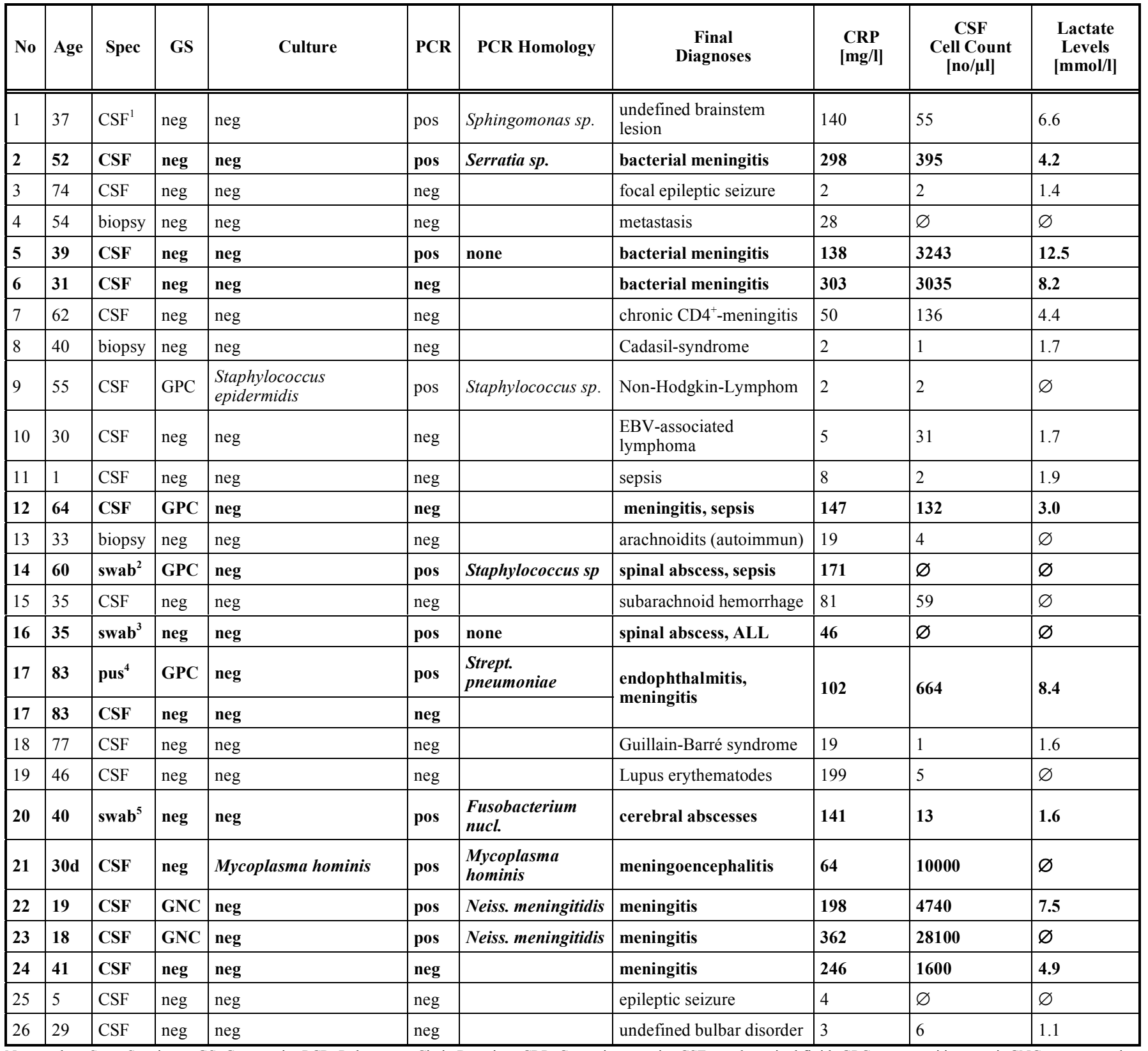

No, number; Spec, Specimen; GS, Gram stain; PCR, Polymerase Chain Reaction; CRP, C reactive protein; CSF, cerebrospinal fluid; GPC, gram positive cocci; GNC, gram negative cocci; pos, positive; neg, negative; $\varnothing$, not done; Staph, Staphylococcus; M, Mycoplasma; ALL, acute lymphocytic leukemia; nucl, nucleatum; CADASIL, cerebral autosomal dominant arteriopathy with subcortical infarctions and leukoencephalopathy; ${ }^{1}$ shunt catheter; ${ }^{2}$ intervertebral disc; ${ }^{3}$ vertebral abscess; ${ }^{4}$ vitreous; ${ }^{5}$ cerebral abscess.

patient with meningoencephalitis, two patients with spinal and one with multiple brain abscesses (Table 1).

All of them showed elevated C-reactive protein levels, ranging from 46 to $362 \mathrm{mg} / \mathrm{l}$. The cell count of the cerebrospinal fluid (CSF) in patients with meningitis revealed 132 to 28,100 cells/ $\mu 1$. Ten of the twelve patients with bacterial CNS infection were already on effective antibiotic treatment at the time of specimen collection. In this group, nine positive PCR results were obtained. In seven cases, the sequences could be aligned with known sequences and were identified as Neisseria meningitidis (2), Mycoplasma hominis (1), Fusobacterium nucleatum (1),
Streptococcus pneumoniae (1), Staphylococcus sp. (1) and Serratia sp. (1).

Mycoplasma hominis was the only germ of this group which could be cultivated, but this took two additional days as compared with PCR. In patient 17, we obtained two specimens, fluid aspirated from the vitreous body, and CSF. In spite of elevated cell counts, both the PCR and the culture failed to detect any bacteria in the CSF. However, microscopy of the ocular fluid of this patient revealed the presence of gram positive cocci. Whereas the culture remained negative but Streptococcus pneumoniae was detected by PCR. Follow-up of the remaining 14 patients excluded bacterial infection of the CNS. But PCR in this 
group yielded two positive results with sequence homology to Sphingomonas sp. and Staphylococcus sp. The latter finding was confirmed by culture and could be identified as Staphylococcus epidermidis.

\section{DISCUSSION}

Even the limited number of 27 samples in our consecutive series showed 11 positive PCR results leading to the identification of nine bacteria after sequencing, with a spectrum of six different species. All bacteria found correlated well with the clinical picture: Fusobacterium nucleatum - abscesses, Mycoplasma hominis meningoencephalitis in a newborn, Neisseria meningitidis, Streptococcus pneumoniae - meningitis, Serratia sp. meningitis with sinusitis, Sphingomonas sp. - contamination, Staphylococcus $s p$. - as contamination as well as a pathogen in an abscess [2]. Except Sphingomonas sp. and Staphylococcus sp. (in one case) all PCR findings were clinically relevant. In three cases the antibiotic treatment was optimized due to the revealed results (patient 2, 20, 21). Furthermore, additional security was gained in clinically critical situations.

Of the 12 patients with bacterial infection of the CNS, 10 received effective antibiotic treatment already at the time samples were taken. In this particular group, PCR was clearly superior to conventional microbiological methods ( 9 versus 1) in detecting bacteria from CSF (5 versus 1) [3-6] or from swabs, pus or biopsy (4 versus 0 ) $[7,8]$. The bacteria found most frequently like Staphylococcus, sp., Strept. pneumoniae, Serratia sp. and Neisseria meningitidis are usually easy to culture. But the need of rapid antibiotic treatment especially in patients with bacterial CNS infection interferes with the conventional microbiological method of culture and makes the PCR more reliable. We found two pathogens by PCR: Fusobacterium nucleatum [9] and Mycoplasma hominis, which are often missed by culture in the absence of particular non-standard growing conditions. Surprisingly, only Mycoplasma hominis grew in a culture when supplementary growth conditions were provided. In two cases, sequencing failed due to insufficient amplicons (patients 5, 16). Further problems with sequencing included the incapability to identify to species-level (patients 9, 14) and ambiguous sequencing results, which is rarely the case in CNS infections [10]. One frequently mentioned advantage is the early availability of PCR results versus culture. This was the case in patient 21. The culture of Mycoplasma hominis took four days, while results from 16S rDNA PCR and sequencing were available by the second day. More than in culture methods, contamination is an important issue of the molecular assay, as seen in patients 1 and 9 . Hence, there should be careful interpretation of any molecular finding, and only in tandem with other laboratory findings, such as culture, immunological and biochemical markers, and the clinical scenario of the patient [11].

In conclusion, broad-range PCR with sequencing is very useful when antimicrobial therapy has already been initiated, or when cultures remain negative in spite of suspected bacterial infection. This technique provides the opportunity to identify non-cultivable, uncommon, or even unknown causative bacteria. High costs and the inherent inability to determine susceptibility to antibiotics with this method restrict routine use as a substitute for bacterial culture.

\section{REFERENCES}

[1] Cursons RT, Jeyerajah E Sleigh JW. The use of polymerase chain reaction to detect septicemia in critically ill patients. Crit Care Med 1999; 27(5): 937-40.

[2] Mandell G, Bennett J, Dolin R, Mandell, Douglas and bennett's principles and practice of infectious diseases. PA, Churchill Livingstone: Philadelphia 2005.

[3] Schuurman T, de Boer RF, Kooistra-Smid AM van Zwet AA. Prospective study of use of PCR amplification and sequencing of $16 \mathrm{~S}$ ribosomal DNA from cerebrospinal fluid for diagnosis of bacterial meningitis in a clinical setting. J Clin Microbiol 2004; 42(2): 734-40.

[4] Banks JT, Bharara S, Tubbs RS, Wolff CL, Gillespie GY, Markert JM Blount JP. Polymerase chain reaction for the rapid detection of cerebrospinal fluid shunt or ventriculostomy infections. Neurosurgery. 2005; 57(6): 1237-43; discussion 1237-43.

[5] Pandit L, Kumar S Karunasagar I. Diagnosis of partially treated culture-negative bacterial meningitis using 16S rRNA universal primers and restriction endonuclease digestion. J Med Microbiol 2005; 54(Pt 6): 539-42.

[6] Welinder-Olsson C, Dotevall L, Hogevik H, et al. Comparison of broad-range bacterial PCR and culture of cerebrospinal fluid for diagnosis of community-acquired bacterial meningitis. Clin Microbiol Infect 2007; 13(9): 879-86.

[7] Tsai JC, Teng LJ, Hsueh PR. Direct detection of bacterial pathogens in brain abscesses by polymerase chain reaction amplification and sequencing of partial 16S ribosomal deoxyribonucleic acid fragments. Neurosurgery 2004; 55(5): 115462.

[8] Kupila L, Rantakokko-Jalava K, Jalava J, et al. Aetiological diagnosis of brain abscesses and spinal infections: application of broad range bacterial polymerase chain reaction analysis. J Neurol Neurosurg Psychiatry 2003; 74(6): 728-33.

[9] Boden K, Joachimski F, Ewald C, et al. Multiple intracerebral lesions. Identification of the causative agent by $16 \mathrm{~S}$ rDNA-PCR. Nervenarzt 2006; 77(12): 1473-6.

[10] Xu J, Millar BC, Moore JE, et al. Employment of broad-range 16S rRNA PCR to detect aetiological agents of infection from clinical specimens in patients with acute meningitis--rapid separation of 16S rRNA PCR amplicons without the need for cloning. J Appl Microbiol 2003; 94(2): 197-206.

[11] Xu J, Moore JE, Millar BC, Webb H, Shields MD, Goldsmith CE. Employment of broad range $16 \mathrm{~S}$ rDNA PCR and sequencing in the detection of aetiological agents of meningitis. New Microbiol 2005; 28(2): 135-43.

This is an open access article licensed under the terms of the Creative Commons Attribution Non-Commercial License (http://creativecommons.org/licenses/ by-nc/3.0/) which permits unrestricted, non-commercial use, distribution and reproduction in any medium, provided the work is properly cited. 